\title{
A previously undescribed syndrome of thoracic dysplasia and communicating hydrocephalus in two sibs, one diagnosed prenatally by ultrasound
}

\author{
ROBIN M WINTER*, STUART CAMPBELL†, \\ JONATHAN S WIGGLESWORTH , AND ELIZABETH J NEVRKLA
}

From * the Kennedy-Galton Centre for Clinical Genetics, Harperbury Hospital, Herts, and the Clinicaid Research Centre, Northwick Park Hospital, Harrow, Middlesex; †King's College School of Medicine and Dentistry, London; $¥$ Royal Postgraduate Medical School, Hammersmith Hospital, London; and §Edgwarid General Hospital, Edgware, Middlesex.

SUMMARY We describe two opposite sexed sibs, the offspring of consanguineous Pakistan parents, with a previously undescribed syndrome. The main features are short ribs with a narrove. chest and thoracic dysplasia, mild shortening of the limbs, communicating hydrocephalus, and developmental delay. One sib was diagnosed prenatally by ultrasound at 18 weeks' gestation. The्ట inheritance of the condition is presumed to be autosomal recessive.

This paper describes two sibs with what appears to be a previously unreported autosomal recessive syndrome affecting the skeleton and brain. One case was diagnosed prenatally by ultrasound.

\section{Case reports}

The affected children were the offspring of first cousin Pakistani parents. They have one normal daughter and a further female child died at birth with severe microcephaly and a posterior encephalocele. No necropsy was carried out on this child, but there were no other external abnormalities. Chromosomes ( $\mathrm{G}$ banded) showed a normal female karyotype.

CASE 1

This male infant was born at term by normal delivery weighing $2.92 \mathrm{~kg}$ (10th centile), length $49 \mathrm{~cm}$ (75th centile), head circumference $37 \mathrm{~cm}$ (98th centile). The child was initially jaundiced and hypotonic and was found to have G6PD deficiency. At five months of age he was noted to have a large head (OFC $45 \mathrm{~cm}$; 98th centile), a prominent forehead, frontal cowlick, somewhat depressed nasal bridge, and poor head control. Overall, the facial features were thought to be unremarkable and mainly secondary to possible hydrocephalus. However, brain ultrasound at this

Received for publication 3 July 1985

Revised version accepted for publication 17 January 1986 stage showed ventricular size within normal limit尺 Length was $60 \mathrm{~cm}$ (less than the $3 \mathrm{rd}$ centile), uppe segment/lower segment ratio 1.72 , and the limbs showed mild rhizomelic shortening. The chest was narrow and measured $35 \mathrm{~cm}$ in diameter (less than the 3 rd centile).

He experienced numerous chest infections follow ing an attack of pertussis. A sweat test was norm and the infections were thought to be secondary to his narrow chest. A diagnosis of communicatin hydrocephalus was made by CT scan at eight month after a marked increase in head circumference whic had previously been following the 98th centile; 9 ventriculoperitoneal shunt was inserted. At one year of age he had several short convulsions which were controlled with phenobarbitone. At a development a assessment at 14 months he was unable to sit on h@ own and he was thought to be at a six month level for motor and manipulative skills, speech, compres hension, and play. He had poor righting reflexes with generalised ataxia. In addition he had a bilateral 55 to $65 \mathrm{~dB}$ hearing loss on free field audiometry and brain stem evoked responses with a flat impedanos response suggestive of serous otitis media. At this stage his length was $72 \mathrm{~cm}$ (3rd centile) and th $\bar{E}$ pattern of limb shortening had not changed. He died at 18 months from respiratory failure. Necropsy w not carried out. Chromosomes ( $\mathrm{G}$ banded) showef a normal $46, X Y$ karyotype. 


\section{Radiographs}

At four months (figs 1 and 2) he was noted to have a narrow thorax with short ribs, but the pelvis was normal. The long bones showed mild metaphyseal abnormalities with slight rhizomelic shortening.

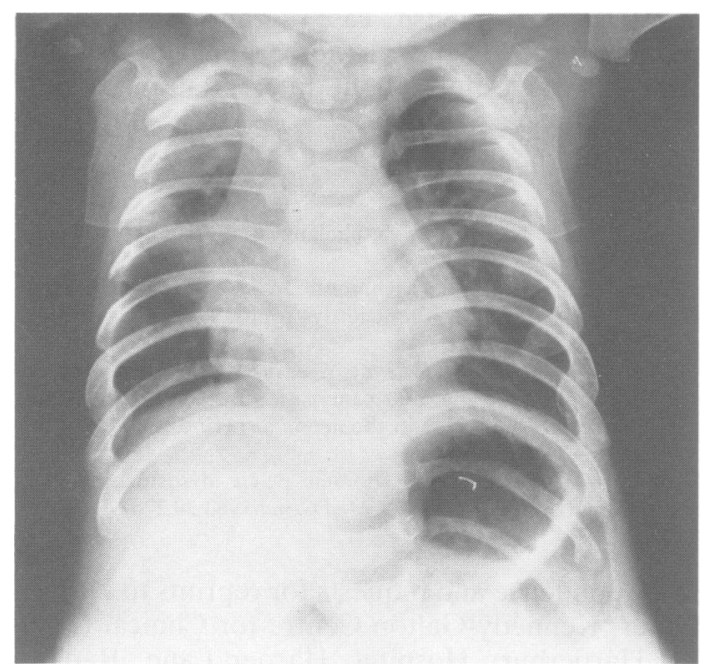

FIG 1 Case 1. AP chest radiograph at four months. Note short, horizontal ribs and narrow thorax.

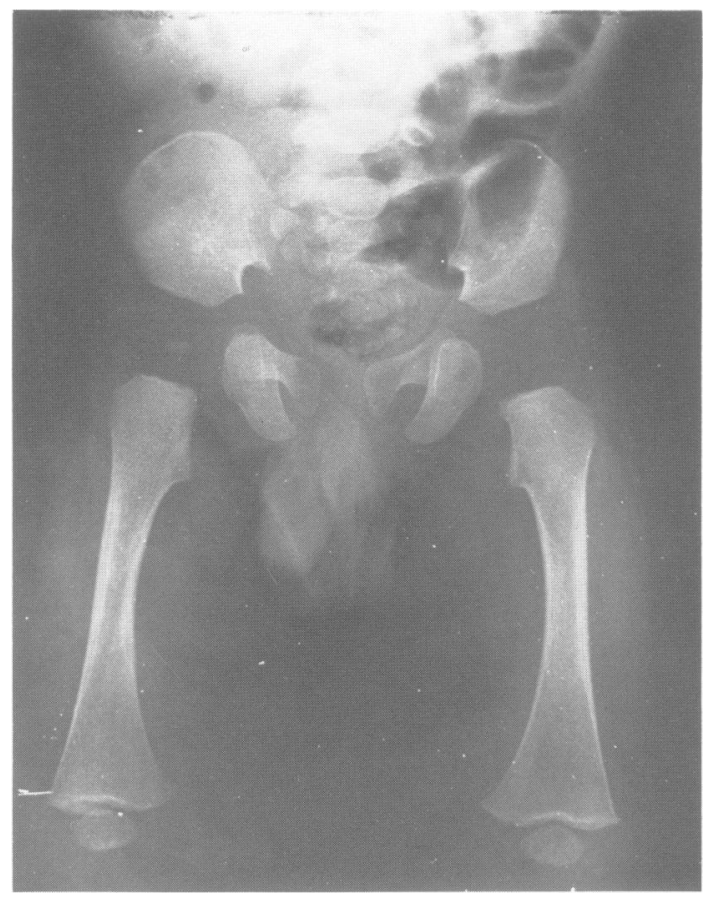

FIG 2 Case 1. AP radiograph at four months. Note small iliac bones and mild metaphyseal flaring of femora.

\section{CASE 2}

This fetus was examined in utero at 18 weeks of pregnancy by means of real time ultrasound. The biparietal diameter was $44 \mathrm{~mm}$, head circumference $161 \mathrm{~mm}$, and abdominal circumference $107 \mathrm{~mm}$. The head measurements were on the mean for the gestational age but the anterior and posterior horns of the lateral ventricles were dilated, being greater than 2 SD above the mean for gestational age. There was no obvious constriction of the rib cage but the chest was in proportion to the abdominal measurement which was below the 5th centile. All the long bone measurements were less than $2 \mathrm{SD}$ below the mean (femur $22 \mathrm{~mm}$, tibia/fibula $18 \mathrm{~mm}$, humerus $22 \mathrm{~mm}$, radius/ulna $16 \mathrm{~mm}$ ). The radii and ulnae were particularly severely reduced being equivalent to the mean length at 14 to 15 weeks' gestation in normal fetuses, whereas the other measurements were equivalent to the mean at 16 weeks' gestation.

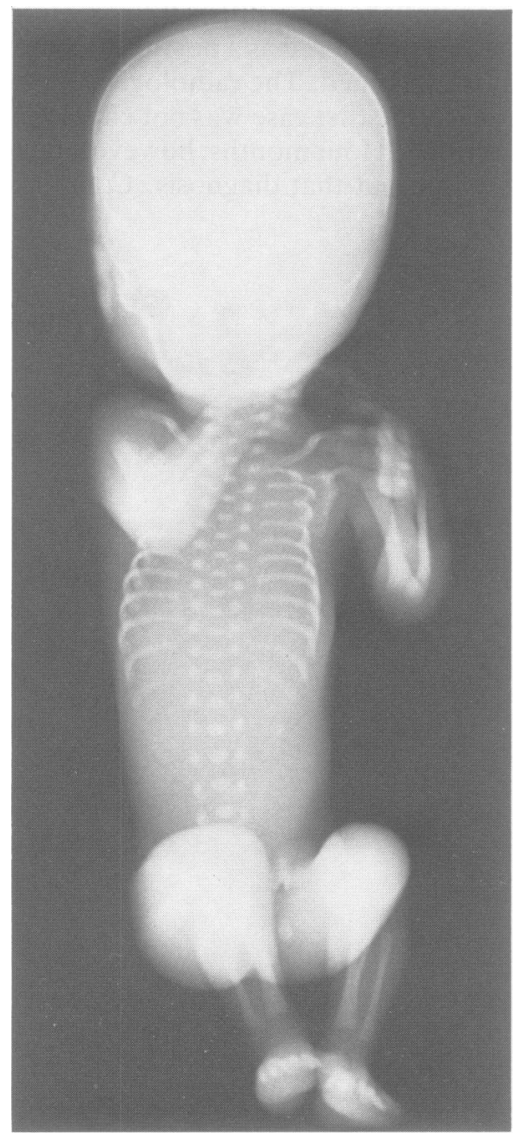

FIG 3 Case 2. Post mortem radiograph at 19 weeks. Note short, horizontal, angulated ribs. 
Chromosome analysis of the amniotic fluid showed a 46,XX karyotype. The pregnancy was terminated.

At necropsy, radiographs (fig 3) showed short, markedly angled ribs with shortening of the long bones. Accurate measurements of the limbs from the fetus were not possible because of fixation, but the limbs appeared short, with distal shortening being more marked than proximal.

Examination of the brain showed moderately dilated ventricles, without other obvious abnormalities of development. Macroscopic and histological examination of the other organs was normal and the fetus was a phenotypic female.

\section{Discussion}

The differential diagnosis in the first case includes Jeune syndrome $\mathrm{i}^{2}$ and other syndromes that can give a severe thoracic dystrophy, such as Schwachman syndrome ${ }^{3}$ and thoracic-pelvic dysostosis. ${ }^{4}$ The significance of the previous sib with posterior encephalocele is difficult to assess. Meckel syndrome was considered as a possible diagnosis, but this was not confirmed. The radiological appearance of the pelvis in the first case was not characteristic of Jeune syndrome at four months; however, this did not completely rule out that diagnosis. Communicating hydrocephalus is unlikely in Jeune syndrome, and the detection of a second affected sib with simila features strongly suggests a hitherto undescribe of syndrome.

The authors would like to thank Dr G Katz fo $\frac{\rho}{2}$ permission to publish case 1 and Professor $\$$ Spranger for reviewing the radiographs of case 1 anकै for helpful suggestions about differential diagnosis. $\vec{\circ}$

\section{References}

1 Langer LO. Thoracic-pelvic-phalangeal dystrophy. Radiolog 1968;91:447.

2 Turkel SB, Diehl EJ, Richmond JA. Necropsy findings in neonatal asphyxiating thoracic dystrophy. $J$ Med Genet 1985 22:112-8.

3 Danks DM, Haslam R, Mayne V, et al. Metaphyseal chondro dysplasia, neutropenia, and pancreatic insufficiency presenting with respiratory distress in the neonatal period. Arch Dis Child 1976;51:697-701.

4 Bankier A, Danks DM. Thoracic-pelvic dysostosis a 'new autosomal dominant form. $J$ Med Genet 1983;20:276-9.

Correspondence and requests for reprints to $\operatorname{Dr} R \mathrm{M}^{\mathrm{N}}$ Winter, Kennedy-Galton Centre for Clinical Gene믐 tics, Harperbury Hospital, Harper Lane, Radlett Herts WD7 9HQ. 